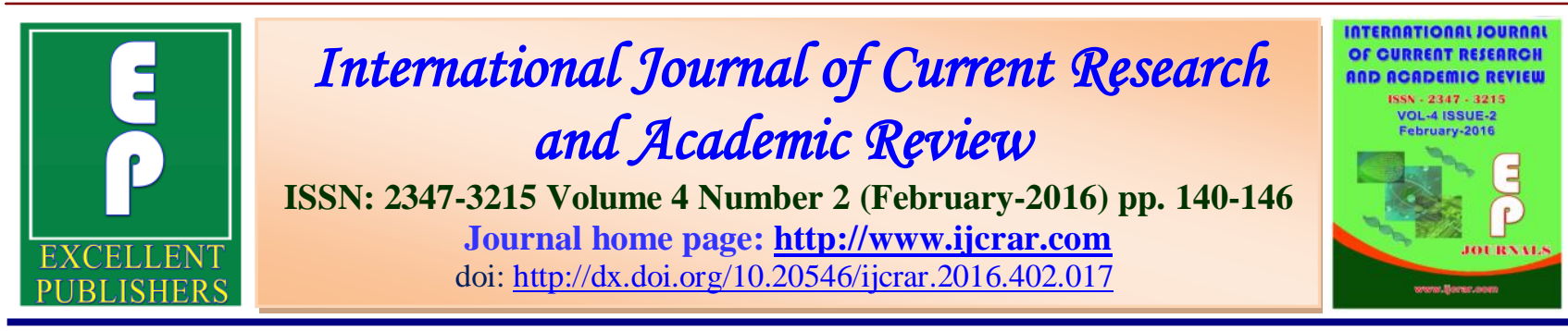

\title{
Recruitment strategies for Human subjects
}

\section{Nandgaonkar Hemant P.*}

M.Sc. (Occupational Therapy - Rehabilitation of the Hand), Assistant Professor, Occupational Therapy School and Center, Seth G. S. Medical College, King Edward Memorial Hospital, Maharashtra University of Health Sciences, Mumbai-400012, Maharashtra, India

\section{KEYWORDS \\ A B $\mathbf{S}$ T $\mathbf{R}$ A $\mathbf{C}$ T}

Recruitment strategies, Ethics

A recruitment strategy is a project-specific plan for identifying and enrolling people to participate in a research study. In the research proposal submitted to ethics committee, the plan should specify criteria for screening potential participants, the number of people to be recruited, the location, and the approach to be used. In this context the study was conducted to find out recent trend in recruitment strategies employed for conducting research on the subjects western region of India. Study design: observational retrospective data analysis Inclusion criterion: Period considered for the analysis: all approved study protocols submitted to ethics committee during January 2013 to December 2013. Exclusion criteria: Studies not involving recruitment of the human subjects. Data analysis reveals that only $8.791 \%$ of the studies mentions about recruitment mechanism in the study. Only $6.59 \%$ of studies described the strategies for the recruitment of the participants. $2.19 \%$ considered the impact of other studies while recruiting the participants. $58.228 \%$ of the participants of these approved protocol belonged to vulnerable population. For making the participation of the subjects voluntary in a research studies done on human subjects, recruitment mechanism and strategies should be clearly mentioned in the research proposal submitted to the ethics committee. Also close attention should be paid while approving the protocols to process of attracting, screening, selecting, and onboarding a qualified person for the research.

\section{Introduction}

"The parliamentary panel points out the careless manner in taking informed consent forms signed by people when they agree to participate in a trial where a medicine is tested on them."[1]
They found the informed consent document were incomplete, some of them were filled by the warden of the hostel. The question came to my mind whether the participants were really informed? How were they 
recruited? Whether autonomy was respected in this study during recruitment? What was the recruitment mechanism or strategy used? How the participants came to know about the project and got interested in this? These are the few questions I have enlisted but the list is not all inclusive.[2]

Whenever the research proposal is submitted to Institutional Ethics Committee, it includes plan of performing the research. This involves, firstly, background and literature search to determine the aims and goals of a research project, and define the target population, i.e. Inclusion Criterion \& Exclusion Criterion. Using these criteria, define the recruitment population, including demographic (occupation, age, gender, race, residence, socioeconomic status, education level, health status, disease states, etc.) and geographic details. If possible, use these details to decide on the best source, of information about the recruitment population, e.g. electoral roll, hospital records, pharmacy records, health services, etc. Taking into account or considerations relating to the recruitment population, decide on one or more recruitment method. This is best done by consulting with the personnel who are likely to do the recruiting. Working within the limits of funding restrictions, factor in a realistic recruitment timeframe and rate, and devise a plan of action to include who will do the recruiting, where to do the recruiting, issues and considerations relating to the particular recruitment population, specific strategies to address these issues and considerations, any ethical or legal considerations, whether and how to compensate participants, the documentations (including ethical and legal documents, data collection documents) required during recruitment, etc.

According to the Consort Statement 2010[3] / Spirit 2013[4], a description of the method of recruitment, such as by referral or selfselection (for example, through advertisements), is also important in this context. Because they are applied before randomization, eligibility criteria do not affect the internal validity of a trial, but they are central to its external validity.

Consort Statement 2010 demands additional information regarding recruitment. This includes ".....information on the settings and locations is crucial to judge the applicability and generalizability of a trial. Were participants recruited from primary, secondary, or tertiary health care or from the community? Healthcare institutions vary greatly in their organization, experience, and resources and the baseline risk for the condition under investigation. Other aspects of the setting (including the social, economic, and cultural environment and the climate) may also affect a study's external validity." SPIRIT (2013) entails mention of strategies for achieving adequate participant enrollment to reach target sample size.

Recruitment is "the action of finding new people to support a cause or join an organization". It is also defined as the Process of attracting, screening, selecting, and onboarding a qualified person for a job. Necessary strategies need to be employed for subject recruitment.

\section{Operational Definition}

In context to prospective research Recruitment is the dialogue which takes place between an investigator \& a potential participant prior to the initiation of the consent process. It begins with the identification, targeting and enlistment of participants (volunteer patients or controls) for a research study. It involves providing information to the potential participants and generating their interest in the proposed study. 
According to Silagy's taxonomy there are different recruitment strategies. They are Medical referral, Personal referral, direct contact (telephone call), community outreach, mass media, referrals, and incentives (e.g. cash or gift card to reimburse participants' time). Sometimes the targeted population might be "Hidden Population" (drug users), or topics might be sensitive like abuse, domestic violence. In these cases the recruitment is done by Snowball method.

Considering all these factors, study was done to find out recent trend in description of different recruitment strategies employed for conducting research on the human subjects.

\section{Methodology}

Study design: observational retrospective data analysis.

The study was done on secondary data. The data was collected from the ethics committee. It was in the form of the research study protocols submitted to Institutional Review Board. To access this data the written permission was taken form Dean, Member Secretary of Institutional Ethics Committee. In addition to the administrative permissions ethics committee approval was taken. Data collection period was from March 2014 - December, 2014.

\section{Inclusion Criterion}

Period considered for the analysis: all approved study protocols submitted to ethics committee. January 2013 to December 2013. Approved projects before 31st December, 2013

\section{Exclusion Criteria}

Studies not involving recruitment of the human subjects.
Authorities were assured about the Confidentiality of the projects. Following measures were taken to maintain confidentiality.

1. De identification of the project proposals - all proposals given new code for data collection and analysis purpose.

2. Data collected was kept in password protected files

3. Never discussed the details of the individual projects apart from the concern Ethics Committee member.

4. Followed the Standard Operating Procedures of Ethics Committee to maintain confidentiality.

5. Identifying information was shredded for appropriate disposal of confidential information.

All the projects were coded and identifiers were not entered in the Case Record Form (Health).

During the data collection phase there were many difficulties, because was which data collection was prolonged. These issues are worth mentioning. They are frequent Staff change of the ethics committee, Lack of staff to get files (it does not mean lack of cooperation), my own busy schedule.

\section{Statistical Methods}

The analysis of the percentage was done in addition to calculating frequency of the records.

\section{Results and Data Analysis}

Population specific strategies were mentioned by only $6.59 \%$ study protocols.

Influencing factors while recruiting the participants were mentioned by two studies i.e. $2.19 \%$. 


\section{Qualitative Analysis}

In addition to the quantitative analysis, qualitative analysis of the description of the recruitment was also done.

1. "All XXXXXX OPD as well as admitted patients will be enrolled.

2. Some protocols directly started with Inclusion and exclusion criterion.

3. Subjects willing to take part in the study \& who meet inclusion criterion, will be included in the study and written informed consent will be taken from each patient.

4. Patients after screening will be admitted in our ward and then subjected to detailed examination....

5. Permission taken from headmaster to conduct the study. The proposal will be put forwarded in monthly parental meeting for their consent......

6. The patients will be counseled for consenting to be a part of XXXX. Anyone eligible for enrolment to the registry would be invited to participate...

Following themes represented of the recruitment strategies mentioned in the study population.

1. It appears that Investigator considers participants as a "Captive".

2. Hardly efforts were taken to attract the participants. Inclusion or exclusion criterion statement is considered as the sole measure for recruitment.

3. Recruitment is not considered a process but structural part of the research proposal.

4. No backup plan.

5. There was no consideration for influencing factors which will affect recruitment process.
India is a colorful canvas portraying a unique assimilation of ethnic groups displaying varied cultures and religions and same is financial capital metro city Mumbai. In this context it is necessary to give close attention to the diversity of the population. Factors such as minorities, such low socio economic status; low literacy; limited access to care; language, family, and community contexts; and attitudes should be taken into consideration during the recruitment process. Knobf (2007) [5] said that researcher should be educated on these various aspects and should mention in the study protocol.

Vulnerable[6]: Patients/clients are in a vulnerable position if they are dependent upon the researcher for their health care. In addition to following the criterion for vulnerability, one needs to consider this aspect during research.

It appears that there is a trend is towards not describing the recruitment strategies. By not describing the recruitment strategies researcher is definitely not thinking from the perspective of the targeted group thus influencing the autonomy of the participant. Establishing trust is the most important factor in research with ethnically diverse populations. Strategies for developing trust include networking ("getting to know"), securing cultural knowledge of the targeted population, and establishing an ongoing relationship that fosters mutual trust and respect...... The goal of the process is mutual respect between researchers and participants, which can be achieved only through the development of competence, understanding, and meaning from the perspective of the targeted group.[7] 
Table.1 Case Record Form

\begin{tabular}{|c|c|c|c|c|}
\hline Sr.No. & Survey question & Yes & No & Remarks \\
\hline 1 & $\begin{array}{l}\text { Are mechanisms mentioned in the study protocol to encourage } \\
\text { recruitment? }\end{array}$ & & & \\
\hline 2 & $\begin{array}{l}\text { Is there mention of about different recruitment strategies tailored } \\
\text { to different racial/ ethnic populations? }\end{array}$ & & & \\
\hline 3 & $\begin{array}{l}\text { Is there mention about the special unit at the hospital that can help } \\
\text { subjects to promote the study to local media and community? }\end{array}$ & & & \\
\hline 4 & $\begin{array}{l}\text { Is there mention about hospital department that have connections } \\
\text { to all of the communities chosen for the study? (E.g. Public Affairs } \\
\text { or Media Relations) }\end{array}$ & & & \\
\hline 5 & $\begin{array}{l}\text { Does study protocol mentions the detailed and piloted plan for } \\
\text { subject outreach for each group chosen? }\end{array}$ & & & \\
\hline 6 & $\begin{array}{l}\text { Is the advertising, brochure, poster, flyers submitted for IEC } \\
\text { review and approval? }\end{array}$ & & & \\
\hline 7 & $\begin{array}{l}\text { Is there mention about a dedicated telephone number and/or email } \\
\text { address for potential participants to learn more about the study and } \\
\text { a response system in place? }\end{array}$ & & & \\
\hline 8 & $\begin{array}{l}\text { Does the study protocol mentions about the conditions that might } \\
\text { affect participant support of project (e.g. the effects of numerous } \\
\text { studies and oversampling, or community activists seeking to } \\
\text { influence Research projects)? }\end{array}$ & & & \\
\hline
\end{tabular}

Table.2 Demographics

\begin{tabular}{|c|l|c|}
\hline Sr. No & Item & Number of studies \\
\hline 1 & Total number of studies records & 148 \\
\hline 2 & Prospective studies & 91 \\
\hline 3 & Retrospective & 18 \\
\hline 4 & Qualitative & 1 \\
\hline 5 & Studies analyzed & 109 \\
\hline
\end{tabular}

Table.3 Recruitment Mechanism Mentioned: Distribution of Studies According to the Category

\begin{tabular}{|l|l|l|l|l|l|}
\hline Sr. No. & Category & $\begin{array}{l}\text { Number of } \\
\text { studies } \\
\text { evaluated }\end{array}$ & $\begin{array}{l}\text { Recruitment } \\
\text { strategy } \\
\text { mentioned } \\
\text { (Number of } \\
\text { studies) }\end{array}$ & $\begin{array}{l}\text { Percentage } \\
\text { with respect to } \\
\text { total number of } \\
\text { studies }\end{array}$ & $\begin{array}{l}\text { Percentage } \\
\text { w.r.t. category }\end{array}$ \\
\hline 1 & Pharma & 2 & 1 & $1.1 \%$ & $50 \%$ \\
\hline 2 & $\begin{array}{l}\text { Government } \\
\text { sponsored }\end{array}$ & 0 & 0 & 0 & 0 \\
\hline 3 & Thesis & 60 & 3 & 3.30 & $5 \%$ \\
\hline 4 & Other academic & 29 & 4 & 4.40 & $13 \%$ \\
\hline 5 & Total & & 8 & $8.79 \%$ & \\
\hline
\end{tabular}


Int.J.Curr.Res.Aca.Rev.2016; 4(2): 140-146

Table.4 Recruitment Strategies for Vulnerable Population

\begin{tabular}{|l|l|l|}
\hline Description & Number of participants & Percentage (\%) \\
\hline Total & 10871 & 100 \\
\hline $\begin{array}{l}\text { Recruitments strategies } \\
\text { mention }\end{array}$ & 1294 & 11.90 \\
\hline Vulnerable population & 6330 & 58.23 \\
\hline $\begin{array}{l}\text { Mention of recruitment } \\
\text { strategies for vulnerable } \\
\text { population }\end{array}$ & 462 & 4.25 \\
\hline
\end{tabular}

The task of tailoring materials for a specific study requires time, insight, and collaboration with members of the ethnic group (in creation, review, and feasibility testing). Researcher should have been prepared for it.

Also, there is no mention of facilities for support in terms of special unit or public affair/ media relations department to promote the study at hospital. Strategies to Promote Recruitment are already mentioned in the literature. Few of them are as follows.

1. Establish trust.

2. Develop an understanding of heterogeneity within and across diverse groups.

3. Dedicate adequate time for the pre recruitment phase.

4. Network in the community.

5. Build community relations.

6. Recruit and train ethnic research team members.

7. Establish respect and value for research team members.

8. Foster personal attributes of flexibility, sensitivity, and adaptability[8]

9. Provide adequate compensation for recruiters.

10. Develop multiple strategies for recruitment.

11. Tailor strategies to the study design.

12. Tailor materials to the target population.
13. Establish community reciprocity.

14. Research mentorship. [8-11]

Infrastructure: There should be special unit at the hospital that can help subjects to promote the study to local media and community.

\section{Conclusion}

Not much attention is paid towards the description of recruitment strategies in a proposed study protocols. In this context, close attention should be paid while approving the protocols to the process of attracting, screening, selecting, and onboarding a qualified person for the research.

\section{Limitation}

The study was done in only one institute and projects of one year were analyzed. This may not represent current trend of recruitment strategies. It just alerts us that such kind of issue exists and its worth having a closer look. Also there might be bias because of the operational definitions. Also stratification according to specialty, department and other criterion was not done.

\section{Implications}

This study highlights the importance of writing recruitment strategies for the human 
subjects more detail within the study proposal. Also it should be scrutinized by the Institutional Review Board during the review process. There should be specific guidelines for description of recruitment strategies by IEC.

\section{References}

1. Datta, P. T. J. (2013, 30th August, 2013). Cervical cancer vaccine study violated law: House panel. The Hindu.

2. PATHAK, B. (2013). Alleged Irregularities in the Conduct of Studies using Human Papilloma Virus (HPV) Vaccine by Path in India. Retrieved from New Delhi, India: http://rajyasabha.nic.in

3. Schulz, K. F., Altman, D. G., \& Moher, D. (2010). Consort 2010 Statement: updated guidelines for reporting parallel group randomised trials. BMJ, 340. doi:10.1136/bmj.c332

4. Chan, A.-W., Tetzlaff, J. M., Altman, D. G., Laupacis, A., Gøtzsche, P. C., Krleža-Jerić, K., Moher, D. (2013). SPIRIT 2013 Statement: Defining Standard Protocol Items for Clinical Trials. Annals of Internal Medicine, 158(3), 200-207. doi:10.7326/00034819-158-3-201302050-00583

5. Knobf, M. T., Juarez, G., Lee, S. Y., Sun, V., Sun, Y., \& Haozous, E. (2007). Challenges and strategies in recruitment of ethnically diverse populations for cancer nursing research. Oncol Nurs Forum, 34(6), 1187-1194. doi:10.1188/07.ONF.1187-1194
6. Sciences, F. o. H. a. L. (2013). Research Ethics Handbook, 2012-13: Oxford Brookes University.

7. Corbie-Smith, G., Thomas, S. B., \& St. George, D. M. M. (2002). Distrust, Race, and Research. Archives of Internal Medicine, 162(21), 2458. doi:10.1001/archinte.162.21.2458

8. McCosker, H., Barnard, A., \& Gerber, R. (2001). Undertaking Sensitive Research: Issues and Strategies for Meeting the Safety Needs of All Participants. 2001, 2(1). Retrieved from http://www.qualitativeresearch.net/index.php/fqs/article/view/ 983

9. ICMR. (2006). Ethical Guidelines For Biomedical Research On Human Participants. New Delhi, India: Director-General, Indian Council of Medical Research.

10. Julion, W., Gross, D., \& BarclayMcLaughlin, G. (2000). Recruiting families.

11. Patel M, D. V., Tennakoon L. . (2003). Challenges in recruitment of research participants. . Adv Psychiatr Treat, 9.

12. Health, N. I. o. M. Points to Consider about Recruitment and Retention While Preparing a Clinical Research Study. Retrieved from http://www.nimh.nih. gov/ funding /grant-writing-andapplication-process/recruitment-pointsto-consider-6-1-05.pdf.

\section{How to cite this article:}

Nandgaonkar Hemant, P. 2016. Recruitment strategies for Human subjects. Int.J.Curr.Res.Aca.Rev. 4(2): 140-146. doi: http://dx.doi.org/10.20546/ijcrar.2016.402.017 